\title{
Governments' Measures to Govern the Coronavirus Crisis and the Lessons Learned
}

\author{
Saqer Sulaiman* \\ * Saqer Sulaiman, University of Public Service, Doctoral School of Public administration Science, \\ e-mail: Saqersul@yahoo.com, ORCID: https://orcid.org/0000-0002-4866-7694
}

\begin{abstract}
Since its appearance in late 2019 in China, the Coronavirus pandemic has posed a real challenge to humanity and governments. No country was safe from the effects of the virus, whether from a medical, economic, or social point of view. In the absence of international coordination, countries began to rely on their own capabilities to curb the pandemic and mitigate its negative effects. To achieve these goals, different strategies and measures have been adopted. Despite the challenges governments faced, these measures definitely helped alleviate the severity of the epidemic and slowed its spread. These measures include, but are not limited to, lockdown, border restrictions, home quarantine, the imposition of wearing masks and social distancing. This crisis stresses the importance of a country's financial, technical and human capabilities in governing crises. Moreover, it revealed that the absence of international cooperation in managing international crises has dire consequences for the international community.
\end{abstract}

Keywords: Coronavirus pandemic, Covid-19, economic implication, governmental measures, crisis

\section{Introduction}

Coronavirus first appeared "on December 31, 2019, when China reported to the World Health Organization (WHO) cases of pneumonia in Wuhan, Hubei Province, China, caused by a novel coronavirus, currently designated 2019-nCoV”. (Phelan et al., 2020, p. 709) "The clinical spectrum of coronavirus infections ranges from mild to critically ill cases". (Yang et al., 2020: 275) The behaviour of the virus was characterised by its rapid spread from one region to another, and its ease of transmission from one person to another, which makes the virus more severe and difficult to control. Thus, the total number of patients has been on a continuous and steep rise since the outbreak of the pandemic. Up to date (November 6, 2020), the total number of confirmed cases worldwide is 49,587,145; the total number of deaths is $1,246,985$; the total number of those recovered is 35,208,404. (Worldometer, 2020) The Corona pandemic has affected all aspects of people's lives, and its negative effects not only represented a health crisis, but also extended to the economic-social, educational and political aspects. There is no doubt that the Coronavirus pandemic has affected the global economy significantly, as global trade rates have decreased as a result of the impact of the Coronavirus pandemic on the economies of many developed countries like the USA, China, Japan, Germany, Italy and thereby. Global growth is projected at 4.9\% in 2020, 1.9 percentage points below the April 2020 World Economic Outlook update. (International Monetary Fund, 2020, p. 1) Along the same 
vein, growth in the group of emerging market and developing economies is forecast at $-3.0 \%$ in 2020, 2 percentage points below the April $2020 \mathrm{WEO}^{1}$ forecast. Growth among low-income developing countries is projected at $-1.0 \%$ in 2020 , some 1.4 percentage points below the April 2020 WEO forecast 2020. (Ibid, p. 6) Moreover, this epidemic has pushed more people to sink below the extreme poverty line. According to the World Bank, "COVID-19 could push 71 million people into extreme poverty in 2020 under the baseline scenario and 100 million under the downside scenario. As a result, the global extreme poverty rate would increase from $8.23 \%$ in 2019 to $8.82 \%$ under the baseline scenario or 9.18\% under the downside scenario". (World Bank, 2020, p. 1)

Education is no exception, the lockdowns and other measures have interrupted conventional education in most countries. Students have had to depend more on their own resources to continue learning online. Furthermore, schools, universities and teachers have had to adapt to new ways of delivering teaching, which they may not have been trained for before. Spending on education is still one of the challenges for families and governments as "the public funds are directed towards health and social welfare. Indeed, long-term public spending on education is at risk despite short-term stimulus packages in some countries". (Schleicher, 2020, p. 5) It is also equally important to mention that the Coronavirus crisis has affected international student mobility. "The crisis has affected the continuity of learning and the delivery of course material, the safety and legal status of international students in their host countries, and students' perception of the value of their degree". (Ibid, p. 9) School closures are also likely to affect the increase in the gender gap in education. It is important to mention that some estimates pointed out the relationship "between the pandemic and the existing gender gap in MENA region in several areas including education, employment, social protection, care work, and gender-based violence". (OECD, 2020, p. 3)

To restrict the spread of the pandemic and mitigate its negative effects, countries have taken certain measures to protect their citizens and their economies. By reviewing the international reactions that accompanied the outbreak of this epidemic in the first weeks and months, one can distinguish different approaches implemented by governments. However, it is important to mention that some countries have been relatively successful in achieving this goal, while others stumble and incurred heavy human and economic losses. In this article, I will try to address this thorny topic and review the countries' responses to the Coronavirus pandemic, taking into account the challenges these countries face in their difficult task to mitigate the effects of this pandemic. I will also try to study the Palestinian case and how the Palestinian Government has dealt with the effects of this pandemic that is still ravaging the world now. Therefore, this article addresses four main questions: What are the strategies used to limit the spread of the pandemic and mitigate its impacts? What are the challenges faced by countries and governments in governing the Coronavirus crisis? How was the crisis managed in Palestine? What are the lessons learned from governing this crisis?

World Economic Outlook update. 


\section{Strategies used to limit the spread and effects of the pandemic}

There are two types of crises; the first type is the expected crises, where the government or organisation prepares plans and interventions in advance to face them in case they occur. The second type is the unforeseen and often confusing crises and has a profound effect on people and institutions. This type is characterised by being sudden and hazy due to the lack of prior information about it, which leads to a loss of control, especially at the beginning of the crisis. The main goal of crisis management is to control the adverse impact of crises and achieving desirable results. "There are four ways through which the organizations can deal with risks: avoidance, transfer, mitigation, and assumption”. (Sulaiman, 2019b, p. 204) The severity of the crisis determines the level and speed of the response. Nevertheless, the degree of severity of the crisis depends on the speed of its spread and the depth of its impact. Coronavirus has had these two features, and this is among the reasons why the World Health Organization considered it a pandemic. Shortly before that, the World Health Organization had declared Coronavirus disease 2019 a public health emergency of international concern. (Sohrabi et al., 2020, p. 4) To control the spread of the virus, countries closed their borders and took measures in the absence of any international coordination to collectively manage the pandemic. Some of these countries succeeded in managing the crisis while others failed. Nevertheless, it must be emphasised that the success or failure in managing the Coronavirus crisis was uneven and relative, so it is not possible to talk about complete success or complete failure. Crisis management methodologies depend on a set of options that must be followed in order to reduce the effects of the pandemic. Although the countries of the world were exposed to the same virus, there was a variation in the response and measures taken by governments around the world. Nevertheless, one can summarise four main schools or approaches that appeared in managing and dealing with this exceptional circumstance that surprised the world. The first approach is confusion and indecision as we saw countries like the USA and the U.K. that received the crisis with hesitation and confusion in decisions. However, later they changed to an approach completely different from what was the case at the beginning of the crisis. The reactions of the people of these countries were a mixture of frustration and loss of confidence in their governments and leaders. However, the second approach is helplessness and panic. People over the world observed countries declaring their internal helplessness and disappointment in their partners and allies who had abandoned them. The citizens of these countries were evident in their criticising of their allies' regional political groupings such as the European Union. As for the third approach, it relied mainly on closures and restrictions. Some countries have adopted a comprehensive closure policy, especially countries suffering from a shortage of medical resources. This approach has been adopted in many Arab countries, such as Jordan and Palestine. The fourth approach in dealing with the Coronavirus crisis is entitled firmness and efficiency through a policy of initiative and transparency where the precautionary measures were gradually developing according to the developments in the epidemiological situation. This approach was adopted by many European countries and some Arab countries, such as Saudi Arabia and the United Arab Emirates. Furthermore, 
with the spread of the Coronavirus in different countries of the world, the most prominent measures taken by countries were as follows:

- Declare a state of emergency in the country.

- Some countries imposed bans on the export of protective equipment and tools to ensure that their domestic needs are covered.

- Many countries imposed travel restrictions on affected countries.

- Some countries banned large gatherings, while only allowed gatherings in very limited numbers.

- Closing schools, universities, sports clubs, restaurants, places of worship and other gathering places. Online learning was also used in schools and universities.

- Opening new hospital departments for Covid-19, as well as establishing field hospitals to accommodate more people infected with the Coronavirus.

- In many countries, hotels and public facilities were used for quarantine purposes.

- Increasing the manufacture of medical equipment, especially masks, sterilisers and ventilators.

- Educating people about the seriousness of the epidemiological situation and the virus and urging them to social distancing as an effective way to limit the spread of the virus.

- Working from home becomes one of the popular methods in many companies and institutions.

- However, the following is a summary of the experiences of some countries to reduce the spread of the Coronavirus pandemic and mitigate its negative impacts.

\subsection{China}

The Chinese experience in confronting the Coronavirus is considered one of the experiences worth studying, especially as it is the first country in which the virus appeared. However, the Chinese performed remarkably compared to other countries. Since the beginning of the outbreak in Wuhan Province, China has begun its plan to confront the spread of the epidemic with a large-scale campaign aimed at isolating the entire region and placing it under quarantine, conducting large-scale Coronavirus tests, and establishing new hospitals to treat and take care of infected people. China has used robots to provide services to people quarantined in hotels and quarantine centres. It has also used technology and smart applications to track down infected and suspected people. The quality of these measures and the speed of decision-making called many to praise the Chinese experience, especially the World Health Organization, which considered the Chinese experience in dealing with the pandemic a role model. Nonetheless, China was criticised by a number of countries, led by the United States, for initially concealing the existence of the virus, and its statistics on the number of victims were in doubt. 


\subsection{Germany}

From the beginning, Germany appears to be in an exceptional condition in response to the Coronavirus epidemic outbreak. During the first few months, the number of people infected with Coronavirus in Germany was the lowest in Europe compared to the number of infected cases. So far (November 6, 2020), the total number of people infected with Coronavirus in Germany has reached 641,362. As for those who fully recovered: 273,500, while the total deaths reached 11,364 . (Worldometer, 2020) Without adopting a comprehensive closure strategy, Germany imposed some restrictions on all its lands to limit the spread of the epidemic, such as closing schools and cultural places, as well as preventing gatherings of more than a specified number of people. What distinguishes the German experience is that it focused on intensifying the examination of the Coronavirus in order to detect the largest possible number of infected persons. Indeed, this strategy has been effective in curbing the epidemic and flattening its curve. There is no doubt that the quality of health services and the availability of the basic requirements of the health system in Germany were crucial to the ability of health authorities to manage the Corona pandemic with minimal losses. Besides, the country's absorptive capacity has contributed to the implementation of social protection programs for the vulnerable groups and those affected by the pandemic.

\subsection{The United Arab Emirates}

The governance of the Coronavirus crisis in the UAE is a distinguished case, as the comparative advantages of the UAE have been employed in curbing the Coronavirus epidemic. According to the adopted strategy, more emphasis was placed on the dynamics and effectiveness of government administration, which enabled the government to efficiently manage the crisis and take the necessary decisions urgently. It is also equally important to mention that the financial capabilities of the country were critical in managing the crisis and taking precautionary measures regardless of the financial cost. The UAE strategy to confront the epidemic is based on the following elements:

- It did not implement complete lockdown, but gradual steps to reduce the spread of the epidemic.

- For detecting cases, it established the largest modern laboratory outside China, to conduct tens of thousands of tests.

- Harnessing technology in restricting the epidemic and managing the crisis such as the use of drones to sterilise cities and mobile pharmacy services to deliver medicines to homes.

- Finally, one of the elements of the UAE strategy was to reduce the economic effects of the crisis on the business sector, as an economic support package was presented to banks and M\&S enterprises operating in the UAE in order to enhance their ability to deal with the negative economic impacts resulting from the Coronavirus crisis. 


\section{The Palestinian experience in governing the Coronavirus crisis}

Like other countries, Palestine has not been spared from this virus and its health, economic and social repercussions. The first six cases of the new Coronavirus epidemic appeared in Palestine on March 5, 2020. The virus was transmitted to them through a group of tourists who visited Bethlehem from Greece. Like other countries, the rate of infection with the Coronavirus is constantly increasing. According to the Palestinian Health Ministry, since the beginning of the outbreak on March 5, 2020, the number of confirmed people infected with the Coronavirus in Palestine stands at 69,181 on November 6, 2020, while the recovered cases are 61,033 and those who deceased is 583 . Since the emergence of the epidemic, the Palestinian Government responded quickly and strictly in order to limit the spread of the virus to protect the life of its people. A state of emergency was declared in Palestine on March 5, and after several days, the borders and land crossings were closed. Furthermore, a set of measures have been applied including restricting people's mobility, closing down cities and preventing movement between provinces. It also includes suspending official departments, government offices, companies and banks for specific periods. Schools, universities, and Kindergarten were closed. In fact, these institutions put more reliance on online learning. Despite the measures taken by the Palestinian government, "the number of infected people started to rise after the accelerated outbreak of the Coronavirus in Israel and the successive transmission of infected cases to the West Bank". (MAS, 2020, p. 3) Actually, Israel became the main source for the spread of the virus in the West Bank through Palestinian workers. In general, the governmental measures to mitigate the effects of the pandemic were based on three tracks: health protection measures, social protection measures and measures to mitigate the economic effects of the pandemic.

\subsection{Health protection measures}

The response of the responsible authorities in the health sector, headed by the Ministry of Health, was characterised by the following:

- Adhere to the instructions of the World Health Organization and the health protocol approved by it regarding the diagnosis, quarantine, treatment and case recovery.

- The diagnosis was carried out using devices and materials that were received from the World Health Organization and under its direct supervision and follow-up. According to the Gazette of Medical Sciences, "laboratory investigation included genomic sequencing, RT-PCR, and serological methods (such as Enzyme-linked immunoassay, ELISA". (Shalalfa et al., 2020, p. 15). As for quarantine for patients and suspects, it was previously done in hotels and certain centres equipped by the Ministry of Health, but due to the increase in cases in the recent period, the shift has been made to the application of home quarantine. As for the period of quarantine, it was initially 14 days, and then it was reduced to 10 days, based on the recommendation of the World Health Organization. A person is considered 
infected if they are tested positive for Covid-19 and if the result is negative, they repeat this to ensure he or she is clear of the virus.

- Certain hospitals have been identified and new hospitals opened to receive and treat Covid-19 patients, and they have also been provided with the necessary equipment and supplies to enhance their ability to provide services to patients.

- Data sharing was one of the main policies of the Ministry of Interior, to achieve this purpose, a website was launched to inform the public about the development of the epidemiological situation in the country and to provide them with data on an on-going basis. Furthermore, sharing information and data with the WHO and other countries was crucial in this regard.

\subsection{Social and economic protection measures}

In order to effectively manage the crisis, the government has taken measures to mitigate the social and economic impacts of the epidemic, especially on the most vulnerable groups, which are more likely to be negatively affected than others, including those in the tourism sector, S\&M companies and irregular employment. Social protection measures: protecting employees by reducing their numbers in their workplaces, whether in the government or private sector, as well as expanding the social protection network to include more beneficiaries, especially those who have lost their jobs due to the epidemic. Additionally, one of the main interventions of the Palestinian Government is community participation in efforts to curb the epidemic. They engaged through the formation of emergency committees to assist the security services and medical staff in carrying out their tasks or by launching community initiatives to raise awareness of preventive measures such as social distancing. Solidarity initiatives have also been launched among members of the Palestinian community, such as the establishment of the "Waqft Ezz" virus relief fund. This fund was established by the government, in cooperation with the private sector to receive donations from individuals, and institutions to help the poor and most affected groups from the pandemic.

As for the macroeconomic level, the Palestinian Government has taken several measures to mitigate the economic effects of the Coronavirus pandemic. In this regard, the Palestinian Government has succeeded, through its successful economic measure, in mitigating the shock of the emerging Coronavirus pandemic, as the negative impact of the epidemic would have been more serious had these measures not been taken. In the first weeks of the pandemic, there was a preference to preserve human life by imposing a comprehensive closure, which greatly harmed the Palestinian economy, but then the government realised the need to restart the economic facilities to alleviate the economic deterioration that began to afflict the local economy.

However, the government's ability to allocate financial and material resources remains the main factor in facing disasters and crises such as the Coronavirus pandemic. When comparing the financial and economic capabilities of the State of Palestine with other neighbouring countries, we notice the difficulty of the situation. The Palestinian Government is already suffering from a financial crisis because Israel has stopped 
transferring clearance revenues, and this leaves it in an unenviable position. It was not able to compensate the workers who were affected by the closure. Likewise, social protection programs did not cover all families affected by the pandemic, and even the "Waqft Ezz", which was established at the beginning of the pandemic, could not collect more than $\$ 17$ million. It was spent on workers and needy families who have been affected as a result of the outbreak of Coronavirus in the Palestinian territories.

\subsection{Challenges faced by the Palestinian Government in governing the Coronavirus crisis}

Despite the efforts made by the Palestinian Health Authority to flatten the curve of the disease in order to reduce the number of cases that need intensive care and thus relieve the pressure on hospitals and health services, achieving this goal is not an easy task and it is actually under threat due to many challenges. These challenges include, but are not limited to, the shortage in financial resources, and shortage in some specialised professions especially in the field of nursing and highly skilled physicians, social culture, in addition to the Israeli occupation obstacles.

- Shortage of resources: The Ministry of Health's expenditures on primary and secondary health care have increased over the years. Financing of the health sector is derived from taxes, health insurance premiums, co-payments, out-of-pocket payments, international aid, and grants as well as nongovernmental resources. The shortage of financial resources is an obvious obstacle to the possible development of the health sector. Indeed, "spending by government, NGOs, UNRWA clinics, and the private sector has increased from $\$ 397.2$ million in 2000 to about $\$ 1,347.4$ million in 2013". (Fanack Newsletter, 2016) Compared to its neighbours, such as Israel, funds are not sufficient to provide real development and stimulation to healthcare in Palestine. In general, the Palestinian health sector is burdened with the volume of services it provides to people, and the Covid-19 pandemic came to increase this suffering, especially in certain areas such as the shortage of doctors and hospital beds. "The total number of doctors working in Palestinian hospitals in 2018 was 5,536 , of which $52.3 \%$ work in public hospitals. As for the number of beds per 100,000 populations, the ratio in the West Bank was 158.8 beds compared to 168.2 beds in the Gaza Strip". (Falah et al., 2020, p. 31) Although the Palestinian Government recruited new doctors at the start of the epidemic, this number is less than required, as is the case with nursing. This indicates that the Palestinian Ministry of Health faces real challenges in providing appropriate medical service to patients, and in the event that the situation worsens and the number of infected cases increases, the ability of the Palestinian health sector to withstand and continue to provide the service will be in doubt.

- Israeli obstacles: The occupation remains the main factor that restricts all areas of Palestinians' lives, physically and/or mentally. This was evident from the arbitrary measures taken by the Israeli authorities against Palestinians before and after the epidemic. The on-going Israeli occupation and violations of Palestinian health 
rights are likely the most important reasons behind the weaknesses in the Palestinian health sector and its inability to improve. (Fanack Newsletter, 2016) The main challenge faced by Palestinians is that Israeli authorities have control over all international borders. This creates a situation in which all goods and machines are subject to inspection by the Israeli army, which tighten the hand of the Palestinian Government to bring machines and medical materials needed to curb the disease. Meanwhile, the time required at the border because of Israeli procedures is the biggest obstacle to bring materials into Palestine. In some cases, as a result of the delay in their delivery to the Palestinian territories due to the obstacles of the occupation, the Coronavirus test kits have expired and were destroyed before reaching Palestinian hospitals. Moreover, the Israeli occupation forces prevent Palestinian security services from applying the law and implementing lockdown measures in Palestinian rural areas that are still under their control. Along the same vein, "Israeli authorities did not commit to its announcement regarding preventing Palestinian workers who decide to stay inside Israel from returning to the occupied Palestinian territories". (MAS, 2020, p. 3)

- Economic challenge: The biggest challenge facing the Palestinian Government is its ability to bear the economic repercussions of the Coronavirus epidemic and mitigate it as much as possible. The economic challenge is significant and as important as the health challenge. Undoubtedly, the pandemic affected many aspects of Palestinian life, on top of which the tourism sector and the small and medium-sized companies had to lay off a number of their workers due to the closure and the decline in production and marketing. Indeed, the most important implications of the Coronavirus crisis were the economic recession that accompanied the health crisis, lockdown measures, and the closure of companies and shops, which led to many employees losing their jobs. Consequently, the unemployment rate increased to unprecedented rates. Additionally, the impact of the Coronavirus pandemic on the labour market shows that "the number of employed persons decreased from $1,009,900$ in the $1^{\text {st }}$ quarter of 2020 to 888,700 in the $2^{\text {nd }}$ quarter of 2020 , by $12 \%$ compared to the $1^{\text {st }}$ quarter of 2020 . Meanwhile, the unemployment rate for males in Palestine reached 23\% compared to $41 \%$ for females". (Palestinian Central Bureau of Statistics, 2020) This data shows that the labour market is the most affected sector during the Coronavirus pandemic. Clearly, the impact of the Coronavirus pandemic will be more severe on the Palestinian economy, as it will add additional economic burdens to the Palestinian economy in the future, especially in light of the modest capabilities of this economy. The precautionary measures taken by the Palestinian Government to combat Coronavirus will lead to an increase in public expenditures as a result of the increase in government spending for the healthcare sector. Health expenditures include purchasing medical equipment, expanding health services, and operating new hospitals and thereof. Furthermore, spending on security services, which is responsible for implementing lockdown and preventive measures, is another burden on the government's budget. As a result of declaring a state of emergency in the Palestinian territories and closing Palestinian crossings and borders with the outside world, the public treasury was 
affected. The suspension of foreign trade has led to a decrease in clearance revenues, which are tax revenues that Israel collects on behalf of the Palestinian National Authority according to the Paris Economic Protocol. "In many cases, Israeli authorities hold over these revenues for political reasons". (Al-Razeq, 2016, p. 6) Undoubtedly, these changes exacerbated the Palestinian economic situation, increased economic stagnation, and reduced the government's ability to fulfil its obligations, especially concerning paying employees' salaries. The Palestinian public debt is also likely to increase, especially, "the Palestinian Ministry of Finance data show that the public debt ratio started from zero, then gradually increased and wobbled according to general economic conditions and international aid". (Sulaiman, 2019a, p. 134) It is worth mentioning that "by the end of 2019, public debt rose to USD 2.8 billion (NIS 9.7 billion), constituting 16.4\% of GDP. This is ascribed to clearance revenues withheld during the year, which has led the government to borrow from banks to meet part of its commitments". (MAS, PCBS, PMA, PCMA, 2019, p. 14) Accordingly, the estimates of economic experts in the first months of the pandemic showed that the loss of the Palestinian economy is expected to be great. "The Palestinian economy expected losses about NIS 33.7 million (USD 9.8 million) per day, which was pumped into the Palestinian economy". (Helles, 2020, p. 4) Despite the negative impact of the Coronavirus pandemic on the Palestinian economy, some have benefited from the spread of this disease. Indeed, some companies have started manufacturing different types of virus prevention tools. For example, the Zaatari factory in the city of Hebron produced masks and marketed them to the local market. Furthermore, the hygiene and sterilisation materials industry has boomed. (Ibid, p. 7)

- Last but not least, and despite the success of the Palestinian Government in managing the Coronavirus crisis so far, it still faces one of the most important challenges, which is to keep the curve of infected cases flattening and stopping the spread of the disease. This requires expanding the virus tracking map and increasing the number of Coronavirus tests. Citizens' commitment to following preventive and public safety measures is another challenge to the success of the flattening strategy.

\section{Lessons learned from the Coronavirus crisis}

Lessons learned are an important tool that must be used continuously to benefit from past experiences. According to Rowe and Sikes (2006), lessons learned are the documented information that reflects both the positive and negative experiences of a project. It is important to note that it is not possible to prevent such epidemics from occurring in the future, but we must learn from our current experience to be more prepared if they arise again. However, the following is a summary of the most important lessons learned from the Coronavirus pandemic crisis.

In the absence of common international mechanisms to confront this crisis, there was reliance on national and local capabilities, and citizens became dependent in the first place 
on the actions of their governments. It seems that Covid-19 has converted regional and international relations. After such a crisis, the tendency to national hard power is now the most dominant approach. It is important to mention that in the absence of external support as the Allies' preoccupation with their problems, reliance on self-capabilities remains the basis for facing crises. Obviously, the success in crisis management depends primarily on national capabilities and the existence of a survival strategy. Most importantly, providing such capabilities and strategy is the task of the government. There is no doubt that surviving the epidemic depends on the single national solid power of the country and the efficiency of its medical system. In developing countries, one of the most important lessons learned is that the security of any country is not only achieved through the accumulation of weapons, but also by strengthening its economic and health capabilities. Thus, one of the lessons learned from this epidemic is to give more attention to scientific research and to harness it to serve people, solve problems and create solutions.

The Coronavirus crisis was a real challenge to the principle of solidarity on which regional and international alliances and partnerships are based, which means that international relations may be undergoing profound transformations in the aftermath of this crisis. However, and regardless of the nature of the international system that will emerge from the Coronavirus crisis, there is no doubt that the winners in managing this crisis are the ones who will shape the world's future. Undoubtedly, the exchange of health information and data between countries facilitated the process of curbing the virus. The Coronavirus crisis showed that there is a state of interdependence between the countries of the world. Moreover, and regardless of the diverse interests and values, the world continues to share the same fate, which creates the need to activate common frameworks that can be relied upon in such crises. Despite the failure of the international community to collectively confront this crisis, regional and international cooperation remains the best and safe option to manage and curb such crises and disasters.

The experiences of countries varied in their management of the Coronavirus crisis. This crisis demonstrated the role of effective management in limiting the spread of the crisis and mitigating its effects. Moreover, countries' experience shows that the speed of response and developing a clear-cut strategy on how to professionally manage the crisis was crucial. For example, some East Asian countries (Japan and Singapore) analysed the situation and responded quickly and were able to limit the spread of the virus, save the lives of their citizens as well as reduce their economic losses. Meanwhile, countries like the United States, Italy and Spain underestimated the crisis and responded too late. Even though these countries possess highly efficient healthcare systems, they were not able to curb the pandemic and incurred huge human and economic losses. "The American case represents a special experience in managing the crisis, despite all the measures that were taken at the federal and local levels, these efforts were described by some experts as the most dangerous crisis facing President Trump". (Sudairy, 2020) It is important to emphasise that effective crisis management must have the following characteristics: the existence of a clear vision and specific goals; the existence of coordination and integration between the various institutions; an efficient crisis management team; the existence of a professional operating system that improves the optimisation of resources and applies best practices. 
The Coronavirus crisis has highlighted the danger of weapons of mass destruction, including biological weapons, as a threat to human civilisation. Besides, the danger of epidemics is increasing in light of globalisation and the ease of movement from one place to another around the world, which facilitates the spread of the virus. There is no doubt that this represents a challenge to the human being that did not exist in the past. The Coronavirus that began in China at the end of 2019 spread over the world within a short period.

As for the overlap between crises and politics, this crisis shows the extent to which a politician can use the crisis for political reasons. It also affected international relations, especially between major countries such as the United States and China. This tension was evidenced through China's announcement that Americans had transferred the disease to the Chinese city of Wuhan, which is an accusation that the United States had exported the disease to China. On the other hand, the U.S. President called the virus "the Chinese virus". Moreover, the U.S. President accused China of concealing the spread of the virus and did not inform international organisations and other countries in time to take preventive measures.

This crisis sheds more light on the role of civil society organisations, the private sector and volunteer work during crises, which greatly supports the role of government agencies, and this has been demonstrated through donation campaigns to help those affected by the pandemic and volunteer work to educate people and help patients in many countries.

The Coronavirus crisis demonstrated the importance of the role of the media and social media in managing crises. Such epidemics existed in the past and were more dangerous than they are today, as there were no laboratories, technology, or media to guide and educate people to avoid their risks. In the Coronavirus pandemic, there was a heavy reliance on social media platforms to reach as many people as possible to send messages related to the developments of the pandemic and to educate them about prevention measures. Although these means are distinguished by their ability to reach large numbers of people, they are also effective and inexpensive tools, given the scarcity of resources and the weak capacities of developing countries. Another advantage is the speed in publishing and mobilising public opinion.

The Covid-19 virus has exposed inequalities that were already present in our societies which were exacerbated by lockdowns or other changing aspects of our daily life during the pandemic. This crisis sheds light on the most vulnerable and disadvantaged groups. Income inequality causes inequality in the standard of living. The spread of Covid-19 in slums is much faster than in other parts of cities because these slums are built in a way that makes it impossible for social distancing and other precautionary measures. Certainly, it is the responsibility of governments and NGOs to address these grievances and support vulnerable groups.

The Coronavirus Pandemic crisis emphasised the importance of assessing risks, using scientific data in creating evidence-based policies, and making appropriate preparations and responses based on this assessment. Despite the growing awareness of the importance of data in policy-making and the preparation of evidence-based interventions, providing this data remains a major challenge for many countries, especially developing countries, as these countries are unable to allocate sufficient resources to collect data on various human 
phenomena. The Coronavirus pandemic has added more difficulties in terms of surveys and data collection in these countries. According to a survey conducted in May 2020, 96\% of national statistical offices partially or completely stopped collecting face-to-face data at the height of the epidemic. (United Nations Statistics Division, 2020) The lack of realistic and sound data on many marginalised groups such as persons with disabilities and the elderly, as well as gender-based marginalisation, lead to the further deterioration of their cases as a result of the lack of data clarifying their status.

\section{Conclusion}

The adverse event may have one of the following negative effects: health crisis, financial losses, disruption to work, difficulties in education and mobility barriers thereof. However, all these effects accompanied the Coronavirus pandemic simultaneously. Undoubtedly, the rapid and widespread spread of the virus in various countries of the world has resulted in human and economic losses. Indeed, tens of millions of workers around the world have lost their jobs and become unemployed. The response of governments to the epidemic varied between a rapid response, where strict measures were imposed to preserve people's lives, and others that were characterised by the gradual application of measures to achieve harmony between preserving people's lives and preventing the collapse of the economy. Obviously, the Coronavirus pandemic has led to an increase in unemployment rates, as well as a significant increase in the number of people below the poverty line. This undoubtedly increases the challenges facing countries, especially developing countries that are already suffering from limited resources.

The experiences of countries indicated that there are countries that succeeded in managing the Coronavirus pandemic through the application of rapid measures and innovative policies that were based on an increase in the number of Coronavirus tests and follow-up procedures for infected cases, as is the case in Japan, Singapore and Germany, while there are countries that failed, such as the United States. However, the safest measure to mitigate the impact of this virus is to take preventive measures until the vaccine or appropriate treatment is discovered. The epidemic has also shown the weakness of the health system, whether at the global or national level, in curbing the epidemic. In addition, the response in some countries was slow, which facilitated the spread of the virus. One of the conclusions that can be drawn from the Coronavirus pandemic is the importance of social media and data management in controlling the pandemic and thus reducing its negative impacts. It is also worth mentioning that the Coronavirus pandemic has revealed that national hard powers and self-reliance are key factors in countries' ability to endure and overcome difficulties and crises. Finally, the measures taken by countries to deal with such crises must be transparent and must depend on sharing information with local society and international institutions, as well as possessing trained competencies capable of dealing with extraordinary situations.

The response of the Palestinian Government to the Coronavirus epidemic was very fast, which contributed to reducing the number of infected cases, especially in the first wave of the epidemic. However, the government measure and lockdown adversely affected 
the Palestinian economy and increased the rate of unemployment and poverty among Palestinians. Palestine is an unstable country that has suffered from crises for a long time, yet the implications of the Coronavirus pandemic have made matters worse. Sectors such as health, the economy and tourism were among the sectors most affected by the pandemic.

\section{References}

Al-Razeq, A. O. (2016). Assessing Fiscal Policies of the Palestinian National Authority. Palestine Economic Policy Research Institute (MAS).

Falah, B., Meshal, J., \& Betawi, W. (2020). Palestinian Health Sector Assessment: Macro-Analytical Study. Palestine Economic Research Institute. www.mas.ps/files/server/2020/healthsectorstudyEnglish.pdf

Fanack Newsletter (2016). The health sector in Palestine. https://fanack.com/palestine/governance-and-politicsof-palestine/the-health-sector-in-palestine/

Helles, R. (2020). The Economic Repercussions of the Coronavirus on the Palestinian Economy. Democratic Arabic Centre for Strategic, Political and Economic Studies. (Translated from Arabic.) https://democraticac. $\mathrm{de} / \mathrm{p}=69086$

International Monetary Fund (2020). World Economic Outlook update, June 2020. www.imf.org/en/Publications/ WEO/Issues/2020/06/24/WEOUpdateJune2020

OECD (2020). COVID-19 crisis in the MENA region: impact on gender equality and policy responses. https:// read.oecd-ilibrary.org/view/?ref=134_134470-w95kmv8khl\&title=COVID-19-crisis-in-the-MENA-regionimpact-on-gender-equality-and-policy-responses

Palestine Economic Policy Research Institute (MAS), Palestinian Central Bureau of Statistics (PCBS), Palestine Monetary Authority (PMA), \& Palestine Capital Market Authority (PCMA) (2019). Economic Monitor 60. www.mas.ps/files/server/20200209151855-1.pdf

Palestine Economic Policy Research Institute (MAS) (2020). Economic Monitor, Special Supplement 2020, Preliminary Assessment of the Possible Impacts of COVID-19 Health Crisis on the Palestinian Economy. www.mas.ps/files/server/2020/monitorSupplement\%20En\%20d1\%20RK\%20clean.pdf

Palestinian Central Bureau of Statistics (PCBS) (2020). Press Release on the Results of the Labour Force Survey Second Quarter (April-June, 2020) Round. www.pcbs.gov.ps/site/512/default.aspx?lang=en\&ItemID=3809

Phelan, A. L., Katz, R., \& Gostin, L. O. (2020). The Novel Coronavirus Originating in Wuhan, China: Challenges for Global Health Governance. Jama, 323(8), 709-710. https://doi.org/10.1001/jama.2020.1097

Rowe, S. F. \& Sikes, S. (2006). Lessons learned: taking it to the next level. Paper presented at PMI Global Congress 2006. Seattle (WA), Project Management Institute.

Schleicher, A. (2020). The Impact of COVID-19 on Education: Insights from Education at Glance 2020. OECD. www.oecd.org/education/the-impact-of-covid-19-on-education-insights-education-at-a-glance-2020.pdf

Shalalfa, N., Kaila, M., Shakhra, K., Odah, A., Heeh, I. A., \& Amro, W. (2020). Novel Corona Virus Outbreak in Palestine. The Gazette of Medical Sciences, 1(3), 13-17. https://doi.org/10.46766/thegms.virology.20072407

Sohrabi, C., Alsafi, Z., O’Neill, N., Khan, M., Kerwan, A., Al-Jabir, A., \& Agha, R. (2020). World Health Organization declares global emergency: A review of the 2019 novel coronavirus (COVID-19). International Journal of Surgery, 76, 71-76. https://doi.org/10.1016/j.ijsu.2020.02.034

Sudairy, N. (2020, April 20). International relations at the time of Corona challenges and strategies. Journal of Law and International Business. (Translated from Arabic.) www.droitetentreprise.com/?p=18983

Sulaiman, S. (2019a). Public Administration in Palestine. AARMS-Academic and Applied Research in Military Science, 18(1), 129-136. https://doi.org/10.32565/aarms.2019.1.8

Sulaiman, S. (2019b). Risk Management in Palestinian Institutions. Repüléstudományi Közlemények, 31(2), 203-210. https://doi.org/10.32560/rk.2019.2.15 
United Nations Statistics Division (2020). COVID-19 widens gulf of global data inequality, while national statistical offices step up to meet new data demands. http://covid\%2019\%20response.unstatshub.org/ statistical-programmes/COVID19-nso-survey/

Worldometer (2020). COVID-19 Coronavirus Pandemic. www.worldometers.info/coronavirus/

World Bank (2020). Projected poverty impacts of COVID-19 (Coronavirus). www.worldbank.org/en/topic/ poverty/brief/projected-poverty-impacts-of-COVID-19

Yang, X., Yu, Y., Xu, J., Shu, H., Liu, H., Wu, Y., \& Wang, Y. (2020). Clinical course and outcomes of critically ill patients with SARS-CoV-2 pneumonia in Wuhan, China: a single-centered, retrospective, observational study. The Lancet Respiratory Medicine, 8(5), 475-481. https://doi.org/10.1016/S2213-2600(20)30079-5 